\title{
Kreatifitas Guru Matematika dalam Mengembangkan Program Pembelajaran secara Daring
}

\author{
Yulia Haryono', Rahmi ${ }^{2}$, Radhya Yusri ${ }^{3}$ \\ yuliaharyono85@gmail.com ${ }^{1}$, rahmisajani@gmail.com², radhya_yusri1989@yahoo.co.id ${ }^{3}$ \\ 1,2,3 Universitas PGRI Sumatera Barat
}

\begin{tabular}{|c|c|}
\hline $\begin{array}{l}\text { Article History: } \\
\text { Received: } 31-12-2021 \\
\text { Revised: } 18-01-2022 \\
\text { Accepted: } 25-01-2022\end{array}$ & $\begin{array}{l}\text { Abstract: The development of learning during the current } \\
\text { Covid-19 pandemic demands there is a change in } \\
\text { learning for teachers and students to adapt existing } \\
\text { situation. Of course, with this, it is undeniable, that very } \\
\text { play a very important role, namely technology, and } \\
\text { information for learning activities at school. One of them is } \\
\text { learning media that can be used as a teacher's teaching } \\
\text { aid to make it easier for student to understand the } \\
\text { material being taught and clarify the presentation of } \\
\text { massages and information from the teacher to the teacher } \\
\text { students so that the teaching and learning process runs } \\
\text { smoothly. Through training this teacher is more motivated, } \\
\text { creative, and innovative in developing online learning so } \\
\text { that students better understand the material at home }\end{array}$ \\
\hline $\begin{array}{l}\text { Keywords: Mathematics, } \\
\text { Creative, Media, Online. }\end{array}$ & $\begin{array}{l}\text { independently and interested in what is presented by the } \\
\text { teacher online. }\end{array}$ \\
\hline
\end{tabular}

\section{Pendahuluan}

Perkembangan pembelajaran saat pandemi covid-19 sekarang ini menuntut adanya perubahan pembelajaran bagi guru dan dan siswa utuk menyesuaikan situasi yang ada. Tentunya dengan hal demikian tidak dipungkiri yang sangat berperan penting sekali yaitu teknologi dan informasi bagi kegiatan pembelajaran di sekolah, hal ini sejalan dengan pernyataan dari Herliandry \& Suban (2020) mengatakan bahwa guru dan siswa harus berinteraksi dan melakukan transfer pengetahuan secara daring. Salah satunya adalah media pembelajaran yang dapat digunakan sebagai alat bantu ajar guru untuk memudahkan para siswa memahami materi yang diajarkan serta memperjelas penyajian pesan dan informasi dari guru ke siswa sehingga proses belajar mengajar menjadi lancar. Keterbatasan indera, ruang dan waktu dapat diatasi dengan media pembelajaran.

Bentuk media pembelajaran yang dilaksanakan saat sekarang ini yang secara daring dapat digunakan dalam pembelajaran matematika berkembang sebagai metode pengajaran baru dengan karakteristik berbeda dari cara pengajaran tradisional mana pun. Namun kesulitan yang ditemukan oleh sebagian guru menurut Sri, Hutagaol, \& Nasari, (2021) adalah guru kesulitan menyampaikan pembelajaran secara daring, siswa tidak aktif dalam mengikuti pembelajaran, susah mendapatkan jaringan internet, harga kuota internet yang mahal. Sehingga dari temuan guru dalam hal teknologi informasi 
bahwa ditemukan persoalan di lapangan berupa sebagai berikut 1) belum memahami mindset pembelajaran daring, 2) kesulitan dalam penyajian materi matematika secara online, 3) tidak memiliki video best practice pembelajaran matematika, 4) kesulitan memilih metode, model dan strategi pembelajaran yang tepat, 5) rancangan tugas yang belum terencana, 6) minimnya sarana dan prasarana. Sehingga perlu suatu pengupayaan untuk mengatasiny baik dari konsep pembelajaran dimana pembelajaran daring merupakan suatu bentuk pembelajaran dengan memanfaatkan teknologi dan informasi. Kemudian komponen pembelajaran daring seperti software, content, hardware, infrastruktur, dan strategi interkasi. Lalu prinsip-prinsip pembelajaran daring ynag meliputi learning is open, learning is social, learning is personal, learning is augmented, learning is multirepresented, learning is mobile. Selanjutnya Jenis komunikasi, terbagi atas dua bagian synchronous dan asynchronous. Maka pembalajaran daring bukanlah sekedar mengupload bahan ajar, pembelajaran daring juga harus disusun secara terencana dan dalam mengajar matematika sebaiknya tidak $100 \%$ daring.

Berdasarkan observasi dan wawancara dengan guru di sekolah SMPN 3 Pantai Cermin kabupaten Solok ditemukan persoalan bahwa sewaktu pandemi melanda siswa belajar dan diberikan tugas dengan melalui via WhatsApp. Kondisi ini menyulitkan guru tentunya mengoreksi tugas-tugas yang diberikan dan terkadang orang tua mengeluh dengan kondisi seperti itu karena orang tua tentunya dipaksa juga harus memahami materi anaknya yang diberikan tugas dari rumah tanpa ada penjelasan dari gurunya langsung. Sehingga perlu diberikan suatu bentuk upaya pelatihan bagi guru dalam menghadapi pembelajaran matematika secara daring. Hal tersebut senada dengan pernyataan dari Safarati (2020) yang mengatakan bahwa hendaknya model pembelajaran yang di berikan guru bersifat daring dan menggunakan bahan ajar yang bersifat aktif, inovatif, dan kreatif agar siswa tdk bosan dengan pembelajaran daring.

Pada era industri 4.0, perkembangan informasi, komunikasi dan teknologi mempunyai pengaruh yang sangat besar dalam kehidupan masyarakat khususnya pendidikan dan pembelajaran. Maka dari itu diperlukan bagi guru untuk bisa menguasai teknologi khususny tekologi pembelajaran, sejalan dengan pendapat Khusniyah \& Hakim (2019) untuk meningkatakan kualitas pembelajaran para guru diperlukan kemudahan menjangkau teknologi. Pembelajaran daring yang dilakukan sekarang ini tidak bisa dihindari, kreatif dan inovatif lah yang mesti guru lakukan (Anugrahana, 2020) agar siswa tidak merasa bosan dan tetap produktif walapun dirumah saja (Handarini \& Wulandari, 2020).

Pembelajaran secara daring mempunyai keunggulan dari pembelajaran konvensional, pembelajaran ini dapat mengaitkan siswa dengan sumber belajar guru yang terpisah secara fisik namun dapat bernteraksi, komunikasi serta kolaborasi langsung synchronous dan tidak https://journal.universitasbumigora.ac.id/index.php/ADMA 
langsung asynchronous (Rosali, Pendidikan, \& Universitas, 2020). Salah satu pembelajaran daring yang dilakukan adalah dengan memberikan kuis secara online dimana merupakan evaluasi bagi siswa setelah pemberian materi sehingga membantu mereka untuk penilaian diri atas tingkat pemahaman saat itu. Berbagai macam bentu kuiz secara online yang sudah tersedia seperti quizizz, kahoot dan lain sebaginya. Aplikasi ini pun dapat membuat siswa senang karena secara tampilan sangat kekinian. Menurut (Adianto, 2020) aplikasi pembelajaran quizizz adalah aplikasi berbentuk kuis atau pertanyaan yang dapat digunakan guru dalam membantu proses pembelajaran dan evaluasi serta memudahkan pekerjaan guru untuk mengetahui tingkat pemahaman siswa dengan cepat dan akurat serta memberikan siswa semangat untuk pengalaman baru dalam belajar.

\section{Metode}

Strategi yang dilakukan berdasarkan masalah mitra sekolah adalah mengadakan sosialisasi dan pelatihan untuk pembelajaran daring dan pembuatan quis online dengan aplikasi quizizz. Pelatihan ini dilaksanakan tiga kali pertemuan dalam jangka waktu satu minggu dengan metode pemberian handout dan bimbingan. Tujuannya adalah agar guru mengetahui bagaimana pembelajaran daring dan bagaimana cara pembuatan evaluasi secara daring dengan menggunakan aplikasi quizizz. Berikut tahapan pelaksanaan kegiatan pengabdian;

1. Persiapan, membuat handout pelatihan, mempersiapkan peralatan penunjang kegiatan, pengurusan administrasi perizinan dari institusi dan mitra sekolah. Melakukan pelatihan terlebih dahulu kepada mahasiswa yang tetrlibat dalam kegiatan pengabdian ini, menentukan jadwal pelaksanaan kegiatan dengan pihak sekolah.

2. Pelaksanaan, melaksanakan kegiatan pelatihan selama tiga kali pertemuan kepada guru SMPN 3 Pantai cermin yang dilakukan dengan menggunakan platform Ms Teams.

3. Akhir, membuat laporan pembelajaran daring dan kuis online.

\section{Pembahasan}

Pelaksanaan pengabdian dilakukan secara daring di SMPN 3 Pantai Cermin Kabupaten Solok dimasa kondisi new normal pandemi Covid-19. Kegiatan awal diskusi dengan pihak mitra sekolah untuk pencerahan terkait pembelajaran di masa new normal. Berdasarkan hasil diskusi tersebut diketahui bagaimana guru merasa kesulitan dalam mengatasi pembelajaran selama daring, belum memahami cara pemikiran pembelajaran 
daring tersebut seperti apa. Hal ini senada dengan Ariesca, Dewi, \& Setiawan (2021) yang mengatakan bahwa kesulitan yang dirasakan guru adalam dalam menentukan penilaian, menyampaikan materi dan mengevaluasi. Guru juga merasa kesulitan dalam penyajian materi matematika secara online, hal ini terungkap bahwasanya guru tidak memiliki video best practice pembelajaran matematika, guru kesulitan memilih metode, model dan strategi pembelajaran yang tepat, perencanaan tugas yang belum matang, serta minimnya sarana dan prasarana. Ditambah juga saat mengevaluasi hasil belajar siswa kebanyakan guru hanya memberikan tugas melalui WhatsApp, sehingga menyulitkan guru untuk mengoreksi tugas-tugas yang diberikan. Guru pun penyampaikan bahwa orangtua murid banyak yang mengeluh, mereka dipaksa memahami materi anak yang diberikan tugas dari rumah tanpa ada penjelasan langsung dari guru.

Setelah diketahui persoalan ditempat mitra serta kebutuhan yang diperlukan dari sekolah, maka tim melakukan diskusi bersama untuk persiapan kegiatan pengabdian ini. Hal ini dilakukan untuk memutuskan topik tentang pembelajaran daring seperti apa yang akan diberikan pada pengabdian ini. Sehingga diputuskan bahwa topik yang disampaikan yaitu bentuk pembelajaran yang memanfaatkan teknologi dan informasi, serta komponen pembelajaran daring seperti software, content, hardware, infrastruktur, dan strategi interkasi. Lalu prinsip-prinsip pembelajaran daring yang meliputi learning is open, learning is social, learning is personal, learning is augmented, learning is multirepresented, learning is mobile. Selanjutnya Jenis komunikasi, terbagi atas dua bagian synchronous dan asynchronous. Maka pembalajaran daring bukanlah sekedar mengupload bahan ajar, pembelajaran daring juga harus disusun secara terencana dan dalam mengajar matematika sebaiknya tidak $100 \%$ daring.

Hasil diskusi dengan tim pengabdian menyatakan bahwa materi nantinya akan di bagi menjadi dua sesi. Sesi pertama tentang persoalan selama pembelajaran daring dan solusiya, dan sesi kedua tentang evaluasi selama pembelajaran daring. Tim pengabdian mulai membagikan deskripsi kerja ke masing-masing individu, mulai membuat proposal, surat menyurat, mempersiapkan bahan atau produk, persiapan link pendaftaran, platform Microsoft Teams, E-sertifikat, serta laporan akhir dan publikasi ke media massa. Tim pengabdian juga membuat bahan presentasi yang berisi materi dan contoh.

Tahap awal mulai sebelum kegiatan pengabdian adalah mengkonfirmasi kembali permintaan sosialisasi dengan terlampir dalam bentuk surat dari mitra sekolah SMPN 3 Pantai Cermin yang berisikan tentang kebutuhan pencerahan terkait pembelajaran daring dengan kelanjutan pembuatan surat pernyataan kesediaan kerjasama dari mitra dalam pelaksanaan program pengabdian. Selanjutnya pengurusan surat menyurat izin melakukan pengabdian kepada pihak kampus. Setelah mendapat persetujuan untuk melakukan https://journal.universitasbumigora.ac.id/index.php/ADMA 
pengabdian tim mempersiapkan bahan atau materi yang akan disampaikan nantinya kepada peserta pengabdian di SMPN 3 Pantai Cermin berupa power point mengenai topik bagaimana permasalahan guru selama pandemi kemudian bagaimana upaya mengatasinya serta bagaimana evaluasi yang dilakukan semasa pandemic beserta contoh. Persiapan link pendaftaran peserta pun dibuat tiga hari sebelum kegitan dimulai dan dishare ke para peserta guru-guru dan juga link daftar hadir peserta di share saat kegiatan berlangsung dan juga e-sertifikat juga dibuat sedemikian rupa untuk peserta yang hadir dan mengikuti hingga akhir segmen.

Tahap kedua yaitu memulai kegiatan pengabdian yang diselenggarakan dengan jumlah peserta sebanyak 12 orang. Agenda acara pembukaan dan kata sambutan dari kedua pihak yaitu sekolah SMPN 3 Pantai Cermin oleh wakil bidang kurikulum Bapak Surya Fitri, SE dan Universitas PGRI Sumatera Barat oleh Ketua Prodi Pendidikan Matematika Ibu Dra. Rahmi, M.Si. Kemudian dilanjutkan penyampaian sosialisasi persoalan pembelajaran daring di sekolah dan solusinya. Penyampaian sosialisasi pertama oleh lbu Dra. Rahmi, M.Si mengenai persoalan apa saja yang muncul selama pembelajaran daring di sekolah, disini peserta menyimak dan memperhatikan sosialisasi yang disampaikan.

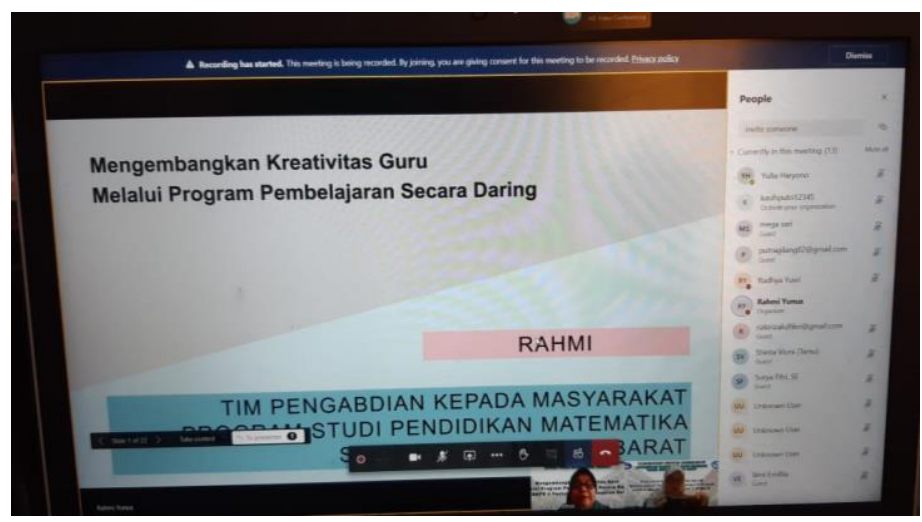

Gambar 1. Dokumentasi kegiatan pengabdian materi pembelajaran daring

Penyajian materi menjadikan guru kreatif selama pembelajaran daring bagi siswa, dengan memberikan suatu bentuk teknologi yang perlu guru ketahui komponen pembelajaran daring seperti software, content, hardware, infrastruktur, dan strategi interaksi serta koneksi internet yang stabil berperan penting dalam pembelajaran daring (Rigianti, 2020). Kemudian jenis komunikasi selama pembelajaran daring tersebut seperti apa yaitu synchronous dan asynchronous. Maka pembelajaran daring bukanlah sekedar mengupload bahan ajar, pembelajaran daring hendaknya disusun secara terencana dan dalam mengajar pelajaran matematika sebaiknya tidak $100 \%$ daring, tentu hal ini yang menjadikan semakin menariknya bagi para guru untuk menyimak materi selanjutnya. Upaya jangka panjang bagi guru nantinya adalah guru dapat melakukan penelitian tindakan kelas, guru dapat meingkatkan kemampuan literasi digital, guru dapat melakukan penelitian eksperimen, serta 
ADMA

Gurnal Pengabdian dan Pemberdayaan Masyarakat
2022, Vol.2, No.2, pp.237-244

Doi: $10.30812 / a d m a . v 2 i 2.1652$

melakukan pengembangan bahan ajar berbasis web.

Penyampaian sosialisasi yang kedua yaitu oleh Bapak Radhya Yusri, M.Pd dimana materi yang disajikan yaitu bagaimana evaluasi pembelajaran yang bisa dilakukan semasa pandemic ini disekolah,

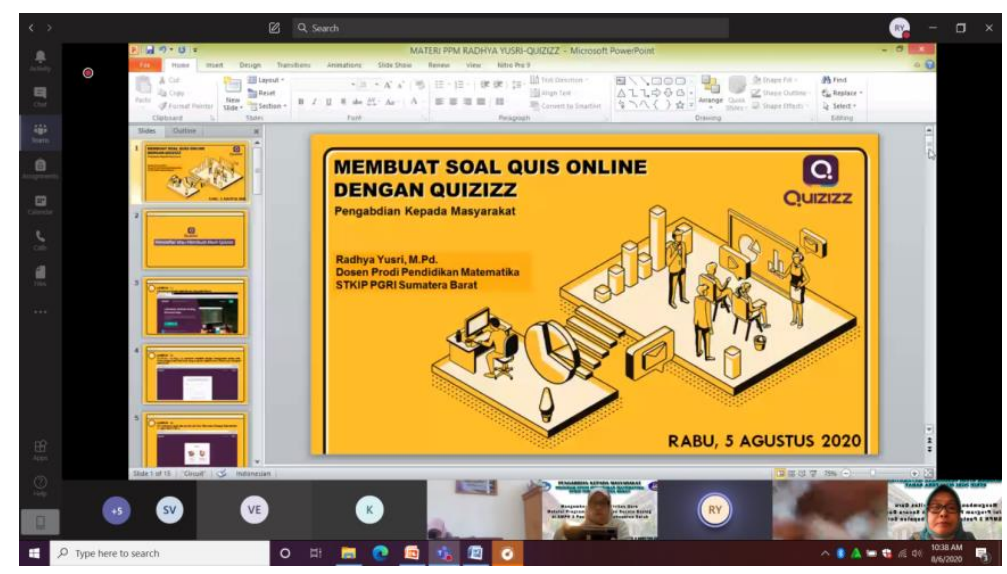

Gambar 2. Dokumentasi kegiatan pengabdian materi kuis online

Beliau menyampaikan bahwa banyak sekali media yg bisa disajikan kepada siswa utk melihat kemampuan belajar siswa mulai dari ada Kahoot, Quiziz, dan lain sebagainya. Pemateri memberikan materi evaluasi pembelajaran secara online menggunakan aplikasi quizizz dimana merupakan salah satu metode pembelajaran berbasis internet yang memungkinkan diketahui tingkat penguasaan masing-masing materi dan masing-masing peserta secara online yang dapat disimpan dalam aplikasi (Mulyati \& Evendi, 2020). Penerapan game quizizz siswa dapat melakukannya di dalam dan luar kelas dengan tampilan yang cukup menarik seperti tampilan tema, meme, music yang bisa menghibur saat pembelajaran (Setiawan, Wigati, \& Sulistyaningsih, 2020). Kemudian pemateri juga menyajikan contoh bagaimana mulai mendapatkan aplikasi tersebut,

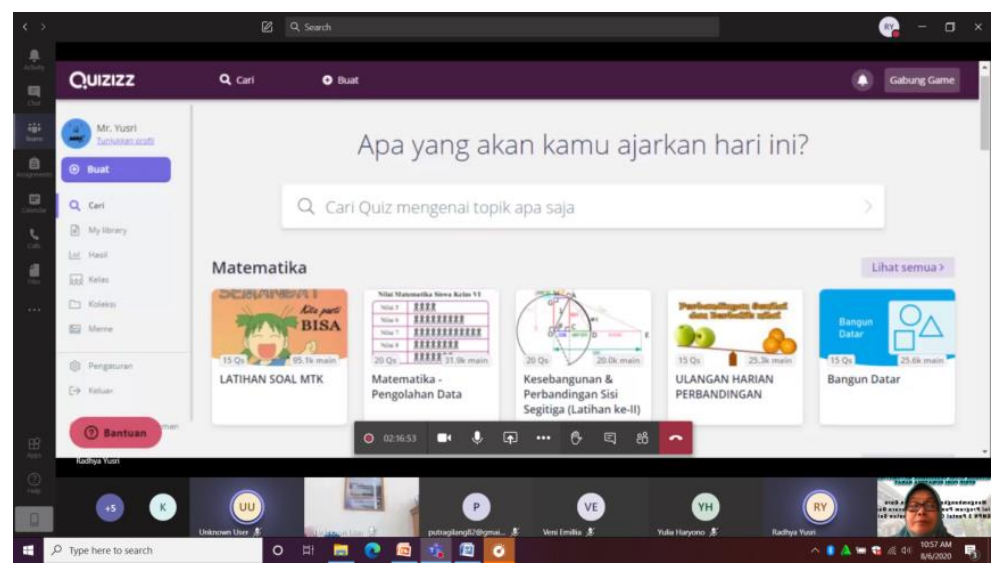

Gambar 3. Tampilan awal materi kuis online

Cara mendaftar, sampai cara mengujicobakan soal yang dicoba praktekan adalah https://journal.universitasbumigora.ac.id/index.php/ADMA 
aplikasi quizizz. Disini peserta menjadi tertarik dengan adanya bentuk nyata aplikasi yang bisa guru gunakan nantinya. Hasil pengamatan selama kegiatan pengabdian berlangsung yaitu ditahap awal guru sedikit kebingunan dan banyak yang menyampaikan bahwa jarigan internet sering tidak stabil. Namun hal tersebut bisa diatasi dengan Peserta banyak bertanya dan mereka langsung mempraktekkan soal-soal yang guru punya untuk nantinya diujikan kepada siswa. Kendala yang dihadapi selama kegiatan pengabdian adalah maslah dengan jaringan internet yang acap kali tidak stabil oleh guru. Aplikasi quizizz memang menuntut jaringan internet yang stabil agar pengoperasiannya lebih menarik bagi siswa. Hal ini sejalan yang disampaikan oleh Mulyati \& Evendi (2020) bahwa kekurangan pembelajaran menggunakan aplikasi quizizz adalah tergantung jaringan internet di tempat masing-masing.

Tahap terakhir yaitu penutupan kegiatan pengabdian dengan penyampaian ucapan terimakasih dari pihak Universitas PGRI Sumatera Barat, dan kesan pesan dari peserta kegiatan pengabdian serta penyampaian penyerahan sertifikat sudah diberikan pada email masing-masing peserta.

\section{Kesimpulan}

Kegiatan pengabdian yang sudah berlangsung dapat disimpulkan bahwa guru masih memrlukan pengetahuan lebih seputar pembelajaran pembelajaran daring bagi pengembangan interaksi guru dan siswa kedepannya yang memang tidak akan lepas nantinya pembejaran daring ini kedepannya. Selanjutnya proses evaluasi yang dilakukan secara daring perlu pemilihan yang tepat bagi guru agar siswa menjadi semangat dalam belajar slah satunya dengan menggunakan aplikasi quizizz.

\section{Ucapan Terimakasih}

Kegiatan pengabdian ini tentunya tidak lepas dari dukungan UP3M Universitas PGRI Sumatera Barat yang telah memberikan izin dan memberikan bantuan tempat kegiatan pengabdian, serta pihak lain civitas akademika Universitas PGRI Sumatera Barat yang telah banyak membantu sehingga kegiatan pengabdian ini berjalan dengan baik dan lancar mengucapkan terimakasih sebesar-besarnya.

\section{Daftar Pustaka}

Adianto, S. (2020). Kajian dan Riset Dalam Teknologi Pembelajaran Penerapan Scientific Dan Cooperative Learning Dengan Quis Online Untuk Meningkatkan Hasil. Jinopet (Jurnal Inovasi Teknologi Pembelajaran), 7(1), 57-65. http://doi.org/10.17977/um031v7i12020p057

Anugrahana, A. (2020). Hambatan, Solusi dan Harapan: Pembelajaran Daring Selama Masa Pandemi Covid-19 Oleh Guru Sekolah Dasar. Jurnal Pendidikan Dan Kebudayaan, 10(3), 282- 
ADMA

Gurnal Pengabdian dan Pemberdayaan Masyarakat
2022, Vol.2, No.2, pp.237-244

Doi: 10.30812/adma.v2i2.1652

289.

Ariesca, Y., Dewi, N. K., \& Setiawan, H. (2021). Analisis Kesulitan Guru Pada Pembelajaran Berbasis Online Di Sdn Se-Kecamatan Maluk. Progres Pendidikan, 2(1), $20-25$. http://doi.org/10.29303/prospek.v2i1.86

Handarini, O. I., \& Wulandari, S. S. (2020). Pembelajaran Daring Sebagai Upaya Study From Home SFH ) Selama Pandemi Covid 19 Pembelajaran Daring Sebagai Upaya Study From Home ( SFH ) ...., 8(1), 496-503.

Herliandry, L. D., \& Suban, M. E. (2020). Jurnal Teknologi Pendidikan Pembelajaran Pada Masa Pandemi Covid-19, 22(1), 65-70.

Khusniyah, N. L., \& Hakim, L. (2019). Efektifitas Pembelajaran Berbasis Daring : Jurnal Tatsqif, 17(1), 19-33.

Mulyati, S., \& Evendi, H. (2020). Pembelajaran Matematika Melalui Media Game Quizizz Untuk Meningkatkan Hasil Belajar Matematika SMP 2 Bojonegara. GAUSS: Jurnal Pendidikan Matematika, 03(01), 64-73.

Rigianti, H. A. (2020). Kendala Pembelajaran Daring Guru Sekolah Dasar Di Kabupaten Banjarnegara. Pendidikan Dan Pembelajaran Ke-SD an, 7(2), 297-302.

Rosali, E. S., Pendidikan, J., \& Universitas, G. (2020). Aktifitas Pembelajaran Daring Pada Masa Pandemi Covid -19 Di. Geography Science Education Journal, 1(1), 21-30.

Safarati, N. (2020). Pelatihan Inovasi Pembelajaran Mengahadapi Masa Pandemic Covid-19. Communnity Development Journal, 1(3), 240-245.

Setiawan, A., Wigati, S., \& Sulistyaningsih, D. (2020). Implementasi Media Game Edukasi Quizizz Untuk Meningkatkan Hasil Belajar Matematika Materi Sistem Persamaan Linear Tiga Variabel Kelas X Ipa 7 Sma Negeri 15 Semarang Tahun Pelajaran 2019 / 2020. Prosiding Seminar Nasional Edusainstek, 3, 167-173.

Sri, A., Hutagaol, R., \& Nasari, J. (2021). Analisis Kesulitan Guru Matematika Kelas VII Dalam Menerapkan Pembelajaran Daring Selama Pandemi Covid-19 Di SMP Nusantara Indah. Jurnal Riset Pendidikan Matematika Jakarta, 3(2), 16-22. 